\title{
Minimally Invasive Versus Open Sacroiliac Joint Fusion
}

\section{Are They Similarly Safe and Effective?}

\author{
Charles G. T. Ledonio MD, David W. Polly Jr MD, \\ Marc F. Swiontkowski MD
}

Published online: 12 February 2014

(C) The Association of Bone and Joint Surgeons $(2) 2014$

\begin{abstract}
Background The sacroiliac joint has been implicated as a source of chronic low back pain in $15 \%$ to $30 \%$ of patients. When nonsurgical approaches fail, sacroiliac joint fusion may be recommended. Advances in intraoperative image guidance have assisted minimally invasive surgical (MIS) techniques using ingrowth-coated fusion rods; however, how these techniques perform relative to open anterior fusion of the sacroiliac joint using plates and screws is not known.

Questions/purposes We compared estimated blood loss (EBL), surgical time, length of hospital stay (LOS), and

Each author certifies that he or she, or a member of his or her immediate family, has no funding or commercial associations (eg, consultancies, stock ownership, equity interest, patent/licensing arrangements, etc) that might pose a conflict of interest in connection with the submitted article.

All ICMJE Conflict of Interest Forms for authors and Clinical Orthopaedics and Related Research editors and board members are on file with the publication and can be viewed on request. Clinical Orthopaedics and Related Research neither advocates nor endorses the use of any treatment, drug, or device. Readers are encouraged to always seek additional information, including FDA approval status, of any drug or device before clinical use. Each author certifies that his or her institution approved the human protocol for this investigation, that all investigations were conducted in conformity with ethical principles of research, and that informed consent for participation in the study was obtained.
\end{abstract}

C. G. T. Ledonio ( $₫)$, D. W. Polly Jr, M. F. Swiontkowski Department of Orthopaedic Surgery, University of Minnesota, 2450 Riverside Avenue, South R200, Minneapolis, MN 55454, USA

e-mail: ledon001@umn.edu

D. W. Polly Jr

e-mail: pollydw@umn.edu
Oswestry Disability Index (ODI) between patients undergoing MIS and open sacroiliac joint fusion.

Methods We retrospectively studied 63 patients (open: 36; MIS: 27) who underwent sacroiliac joint fusion with minimum 1-year followup at our institution from 2006 to 2011. Of those, 10 in the open group had incomplete records. All patients had sacroiliac joint dysfunction confirmed by image-guided intraarticular anesthetic sacroiliac joint injection and had failed nonoperative treatment. Patients were matched via propensity score, adjusting for age, sex, BMI, history of spine fusion, and preoperative ODI scores, leaving 22 in each group. Nine patients were not matched. We reviewed patient medical records to obtain EBL, length of surgery, LOS, and pre- and postoperative ODI scores. Mean followup was 13 months (range, 11-33 months) in the open group and 15 months (range, 12-26 months) in the MIS group.

Results Patients in the open group had a higher mean EBL $(681 \mathrm{~mL}$ versus $41 \mathrm{~mL}, \mathrm{p}<0.001)$. Mean surgical time and LOS were shorter in the MIS group than in the open group (68 minutes versus 128 minutes and 3.3 days versus 2 days, $\mathrm{p}<0.001$ for both). With the numbers available, mean postoperative ODI scores were not different between groups (47\% versus $54 \%, \mathrm{p}=0.272$ ).

Conclusions EBL, surgery time, and LOS favored the MIS sacroiliac fusion group. With the numbers available, ODI scores were similar between groups, though the study size was relatively small and it is possible that the study was underpowered on this end point. Because the implants used for these procedures make assessment of fusion challenging with available imaging techniques, we do not know how many patients' sacroiliac joints successfully fused, so longer followup and critical evaluation of outcomes scores over time are called for. 
Level of Evidence Level III, therapeutic study. See Instructions for Authors for a complete description of levels of evidence.

\section{Introduction}

The sacroiliac joint has been implicated as a source of chronic low back pain in $15 \%$ to $30 \%$ of patients $[2,3,5,7$, $8,11,12,15,19,20,23-25]$. In a recent study by Sembrano and Polly [20], of 200 consecutive new patients examined in a spine clinic with a chief complaint of low-back pain and no prior history of spine, sacroiliac joint, or hip surgery, $65 \%$ were found to have pain attributed to the spine only, while $5 \%$ were attributed to the sacroiliac joint only and $14.5 \%$ were attributed to both.

The mainstay of therapy for disorders of the sacroiliac joint has been nonoperative treatment, including activity modification, NSAIDs, physical therapy, and sacroiliac joint injections [2, 3, 26]. When these modalities fail, traditional open sacroiliac joint arthrodesis may be recommended. However, morbidity with the open technique of sacroiliac joint fusion is not inconsequential, including intraoperative blood loss, multiple-day hospital stay, and limits on postoperative weightbearing. In light of these concerns, recent advances in intraoperative image guidance have led to minimally invasive surgical (MIS) techniques being utilized with increasing frequency over traditional open procedures [14]. While the technique appears promising, to our knowledge, no outcome data are reported in the literature comparing the two surgical techniques with regard to intraoperative blood loss, surgical time, hospital stay, or patient-reported outcomes. We therefore compared estimated blood loss (EBL), length of surgical time, length of hospital stay (LOS), and Oswestry Disability Index (ODI) associated with open and MIS sacroiliac joint fusion techniques using propensity-scorematched cohorts.

\section{Patients and Methods}

This retrospective comparative study was approved by our institutional review board. From 2006 to 2011, 63 patients underwent either open or image-guided MIS sacroiliac joint fusion by one of two senior orthopaedic surgeons. Of those, 10 in the open group had incomplete records. One surgeon (MFS) performed exclusively open operations while the other (DWP) did exclusively MIS. In terms of the surgeons' experience, one surgeon (MFS) has been performing open operations for many years and the other (DWP) has performed some open procedures and has extensive spine experience, including MIS. All patients had sacroiliac joint dysfunction/sacroiliitis confirmed by specific provocative physical examination tests and diagnostic/ therapeutic image-guided sacroiliac joint injections and had failed nonoperative treatment.

We reviewed the medical records of these patients with a minimum followup of 1 year to obtain the following information: demographics (age, sex, BMI), history of spine surgery, EBL, length of surgery, LOS, and pre- and postoperative ODI. EBL was estimated by the surgeon. Length of surgery was calculated from the time of cutting time to closing time as defined by in-house policy. LOS was recorded from day of admission to day of discharge in the hospital records. Preoperative and latest ODI scores were patient derived.

To reduce the influence of selection on the comparison of the two techniques, we used propensity score pairwise matching of patients undergoing MIS sacroiliac joint fusion to the pool of available patients who underwent open sacroiliac joint fusion. To do this, logistic regression was used to develop a propensity score $\left(\right.$ IBM $^{\circledR} \operatorname{SPSS}^{\circledR}$; IBM Corp, Armonk, NY, USA). The propensity score was constructed using the following preoperative variables: age, sex, BMI, history of spine surgery, and preoperative ODI. For this, matching to five decimal points was initially performed, followed by four-, three-, two-, and one-decimal point matching. MIS patients whose propensity scores deviated more than 0.25 from those of open patients were considered unmatched. To ensure good matches, we performed postmatching comparison of mean age, BMI, and preoperative ODI using t-tests and distributions of sex and history of spine surgery using Mann-Whitney U tests. Four patients from the open group and five from the MIS group were unmatched. A total of 38\% (14 of 36) in the open group and $18 \%$ (five of 27) from the MIS group were not included in the analysis.

Table 1. Demographics in patients with MIS versus open sacroiliac joint fusion

\begin{tabular}{llll}
\hline Variable & $\begin{array}{l}\text { Open group } \\
(\mathrm{n}=22)\end{array}$ & $\begin{array}{l}\text { MIS group } \\
(\mathrm{n}=22)\end{array}$ & p value \\
\hline Age (years)* $^{*}$ & $51.0 \pm 9.4$ & $47.9 \pm 13.1$ & $0.361^{\dagger}$ \\
BMI* $^{\text {Preoperative ODI (points)* }}$ & $29.9 \pm 4.0$ & $30.5 \pm 6.1$ & $0.711^{\dagger}$ \\
$\begin{array}{l}\text { Sex (male:female) } \\
\quad \text { (number of patients) }\end{array}$ & $9: 13 \pm 10.8$ & $61.5 \pm 12.5$ & $0.898^{\dagger}$ \\
$\begin{array}{c}\text { Spine surgery history } \\
\text { (number of patients) }\end{array}$ & $11(50 \%)$ & $5: 17$ & $0.201^{\dagger}$ \\
\hline
\end{tabular}

* Values are expressed as mean $\pm \mathrm{SD}$; ‘Student's t-test; ${ }^{\dagger}$ MannWhitney U test; MIS = minimally invasive surgery; ODI = Oswestry Disability Index. 

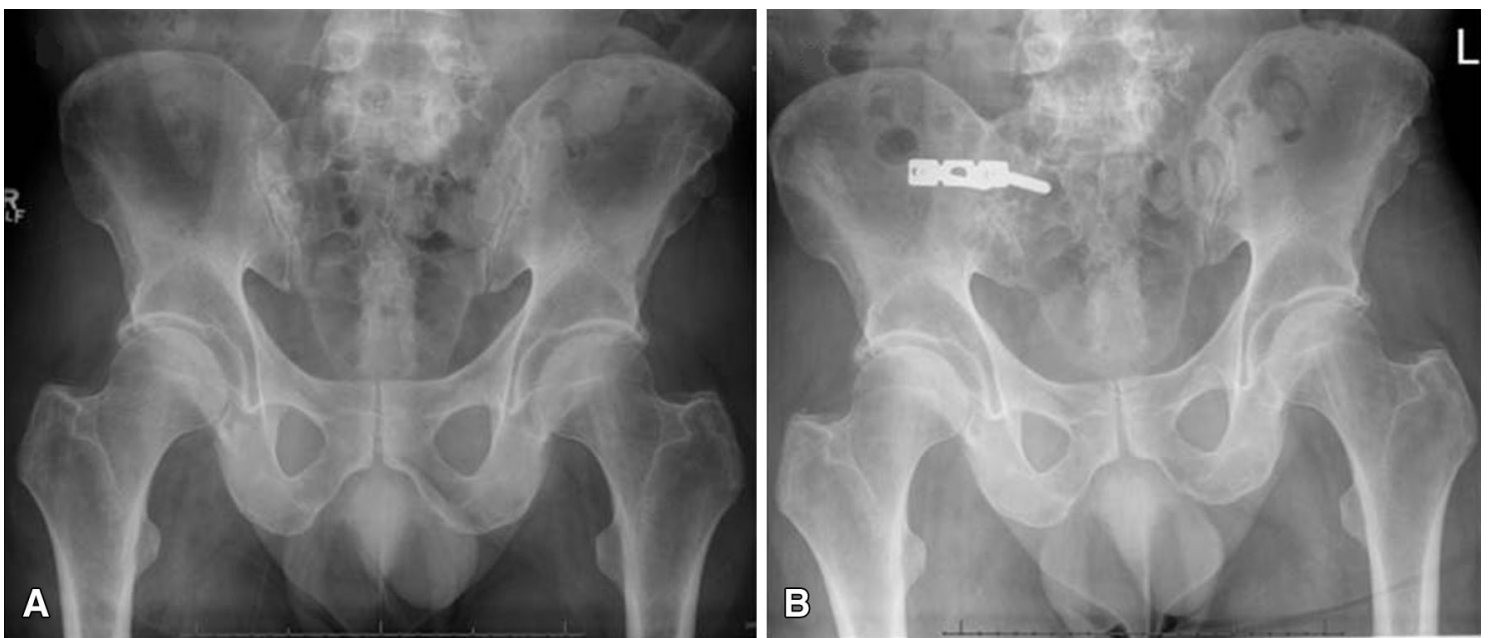

Fig. 1A-B (A) A preoperative radiograph of the pelvis shows no anatomic abnormality. (B) A postoperative radiograph of the pelvis shows a three-hole reconstruction plate spanning the sacroiliac joint.

The results of matching yielded 22 MIS patients, propensity matched to 22 open patients. There were 13 women and nine men in the open group, with a mean age of 48 years and a mean BMI of $30.5 \mathrm{~kg} / \mathrm{m}^{2}$, and 17 women and five men in the MIS group, with a mean age of 53 years and a mean BMI of $30 \mathrm{~kg} / \mathrm{m}^{2}$. Eleven of $22(50 \%)$ patients in the open group and 14 of $22(64 \%)$ patients in the MIS group had a history of spine surgery. None of the procedures were performed on the sacroiliac joint. Mean age, mean BMI, and mean preoperative ODI did not differ between groups $(p=0.361,0.711$, and 0.898 , respectively) (Table 1). The distributions of sex and spine surgery history were also similar between groups $(\mathrm{p}=0.201$ and 0.367 , respectively) (Table 1). These results ensured a good match between the cohorts. Mean followup was 13 months (range, 11-33 months) in the open group and 15 months (range, 12-26 months) in the MIS group.

\section{Open Anterior Sacroiliac Joint Fusion Technique}

The sacroiliac joint was approached anteriorly through an ilioinguinal incision of approximately $20 \mathrm{~cm}$ in length. The skin and subcutaneous tissue were incised sharply. With sharp dissection, the external oblique and gluteal fascia was exposed and an interval developed. The iliacus was elevated from the iliac fossa with a subperiosteal dissection and a retractor placed inside the iliopectineal line of the pelvis. With retraction, electrocautery was used to expose the superior capsule of the sacroiliac joint. Under headlamp illumination, the capsule was removed off the iliac and sacral portion of the sacroiliac joint with a Number 15 blade. A pointed Homan retractor was inserted on the sacral ala after careful exposure. The sacroiliac joint cartilage was resected using a series of curettes and rongeurs removing all cartilage back to the posterior ligament and structures. Bone graft was harvested from the inner table of the ilium and then morselized. All the bone graft was packed into the sacroiliac joint after predrilling both the sacral and iliac sides with multiple $2.5-\mathrm{mm}$ drill holes. A three-hole $4.5-\mathrm{mm}$ reconstruction plate was contoured and fixed with a fully threaded 6.5 -mm cancellous screw on the sacral side and two cortical screws on the iliac side (Fig. 1). The plate was inspected to make sure there was no soft tissue under it or stretched over it. The soft tissues were allowed to fall back in place and a 1/8-inch hemovac drain was placed into the iliac fossa. An absorbable gelatin compressed sponge was placed into the bone graft harvest site. The external oblique and transversalis fascia was repaired to the gluteal fascia with multiple figure-of-eight sutures and wound closed in layers.

Postoperatively, the patients were kept toe-touch weightbearing for 6 weeks. At 6 weeks, the patients were treated with pool therapy for 4 weeks with progressive weightbearing. This was followed by 8 weeks of landbased therapy focusing on core body strengthening.

MIS Sacroiliac Joint Fusion With Three-dimensional CT Image-guided Navigation

The patient, under general anesthesia, was placed in a prone position with hips and knees extended on a Jackson table. A percutaneous pin with a frame registry marker was inserted into the contralateral posterior superior iliac spine. A portable sterile covered CT scan (O-arm) was placed into 
Fig. 2A-D (A) Real-time threedimensional CT-based navigation of percutaneous implant placement across the sacroiliac joint is demonstrated. (B) Intraoperative planning of implant trajectories and subsequent navigated placement are demonstrated. (C) An intraoperative CT scan (using O-arm) of the sacroiliac joint is used to assess implant placement. (D) Postoperative AP and lateral radiographs of the pelvis show three fusion rods across the sacroiliac joint.
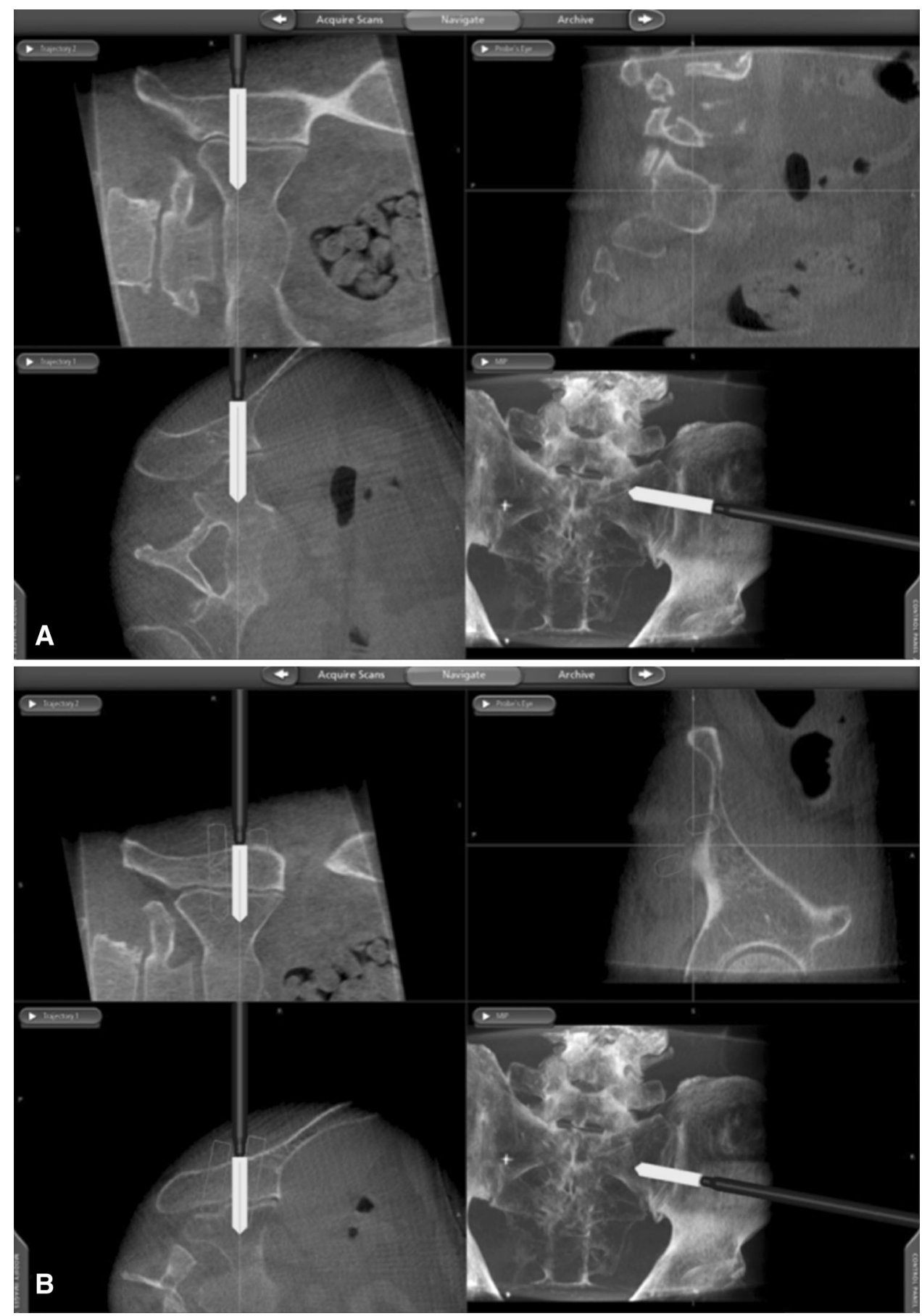

position at the sacroiliac joint. Coronal and lateral fluoroscopic images were taken to verify correct position, followed by a CT scan. Three-dimensional image data were then transferred to a computer workstation (Stealth ${ }^{\circledR}$; Medtronic, Inc, Minneapolis, MN, USA) for navigation. Computer registration of tracked instruments (probe and drill guide) was carried out. Using a navigated probe, approximate implant positions were marked on the skin over the lateral border of the gluteus. Local anesthetic was infiltrated and a 4- to 5-cm incision was made through the skin only. Under image guidance, a registered drill guide was navigated into position and a $\mathrm{K}$-wire placed across the sacroiliac joint (Fig. 2A). This was then checked under fluoroscopy. The soft tissue envelope was then dilated with cannulated serial dilators. Once the surgeon decided that the trajectory was in satisfactory/optimal position (Fig. 2B), implant length was measured and a pilot hole was made using a cannulated drill bit, followed by a cannulated 
Fig. 2A-D continued
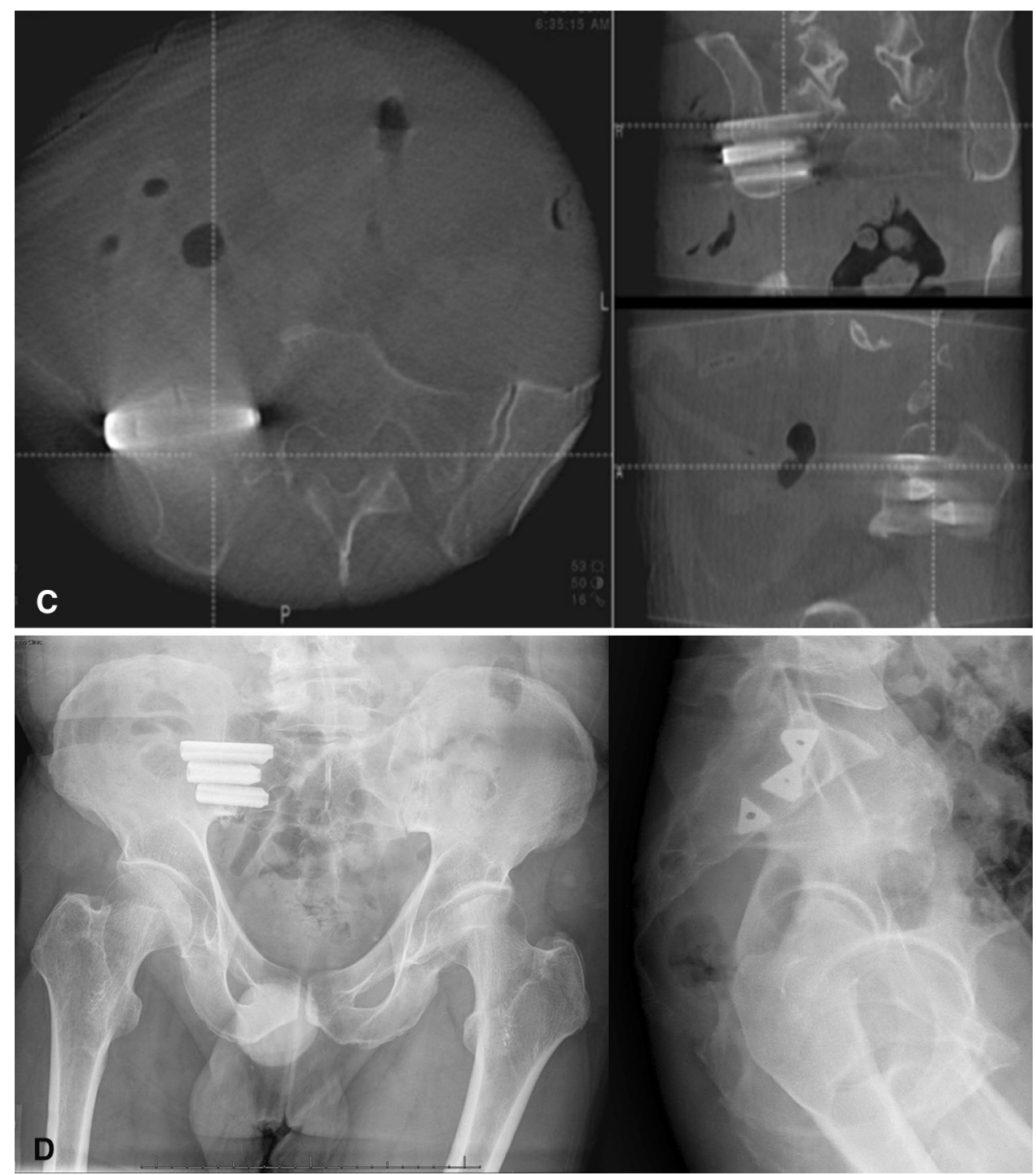

broach. The implant, a triangular plasma-sprayed ingrowth fusion rod (iFuse Implant System ${ }^{\circledR}$; SI-BONE, Inc, San Jose, CA, USA), was then inserted. A total of three fusion rods were typically placed. Two- and three-dimensional imaging was done to check implant position across the sacroiliac joint (Fig. 2C-D). The wound was irrigated and closed.

Postoperatively, patients were kept toe-touch weightbearing for 3 weeks, followed by physical therapy to restore normal gait.

\section{Statistical Analysis}

Descriptive statistics are summarized as mean and SD for continuous variables when indicated, whereas categorical variables are expressed as percentages. We compared quantitative variables using Student's t-test and categorical variables using the Mann-Whitney U test with an alpha set at 0.05. All statistical analyses were performed using IBM $^{\circledR}$ SPSS $^{\circledR}$ software.

\section{Results}

The MIS group had a lower mean EBL at $41 \pm 31 \mathrm{~mL}$ than the open group with $681 \pm 479 \mathrm{~mL} \quad(\mathrm{p}<0.001)$ (Table 2). The mean length of surgery (incision to closure) was shorter for the MIS group at $68 \pm 27$ minutes compared to the open group with $128 \pm 28$ minutes $(\mathrm{p}<0.001)$. The open group had a longer mean LOS at $3.3 \pm 1.1$ days compared to the MIS group with $2.0 \pm 1.5$ days $(\mathrm{p}<0.001)$.

The mean postoperative ODI scores for the open and MIS groups were not different $(47 \% \pm 22 \%$ and $54 \% \pm$ $17 \%$, respectively; $\mathrm{p}=0.272$ ) (Table 2). The ODI 
Table 2. Outcomes in patients with MIS versus open sacroiliac joint fusion

\begin{tabular}{lccr}
\hline Outcome & $\begin{array}{l}\text { Open group } \\
(\mathrm{n}=22)\end{array}$ & $\begin{array}{l}\text { MIS group } \\
(\mathrm{n}=22)\end{array}$ & p value* \\
\hline Estimated blood loss $(\mathrm{mL})$ & $681.8 \pm 479.0$ & $40.5 \pm 31.4$ & $<0.001$ \\
$\begin{array}{l}\text { Length of surgery (minutes) } \\
\begin{array}{l}\text { Length of hospital stay } \\
\text { (days) }\end{array}\end{array}$ & $3.3 \pm 1.1$ & $2.0 \pm 1.5$ & 0.002 \\
Postoperative ODI (points) & $47.4 \pm 21.7$ & $52.0 \pm 16.9$ & 0.272
\end{tabular}

Values are expressed as mean $\pm \mathrm{SD}$; $*$ Student's t-test; MIS $=$ minimally invasive surgery; ODI $=$ Oswestry Disability Index.

improved in 15 of 22 (68\%) patients in the open group, with a mean improvement of 19.8 points from baseline, and in 16 of $22(73 \%)$ in the MIS group, with a mean improvement of 12 points from baseline. The improvement was significant $(\mathrm{p}<0.001)$ for both groups.

There were three complications for the open group: one pulmonary embolism that resolved with treatment and two revisions due to failed implant and nerve root irritation. Similarly there were three complications in the MIS group: one pulmonary embolism that resolved with treatment and two revisions due to halo formation on the sacral side with recurring sacroiliac joint pain.

\section{Discussion}

Although the use of MIS techniques is becoming more common among surgeons [14], it is difficult to determine the effectiveness of MIS techniques for sacroiliac joint fusion compared to open techniques when only observational studies with no control groups are available as evidence. This is especially true when covariates such a history of lumbar spine surgery have been reported to be an important factor in the clinical results of sacroiliac joint fusions after failed nonoperative management [22]. We therefore compared EBL, surgical time, LOS, and ODI associated with open and MIS sacroiliac joint fusion techniques using a study cohort that was propensity score matched to controls for confounding preoperative variables. Adequacy of the matching was further validated by comparison of the preoperative variables, which showed no differences, implying a reasonably matched cohort was achieved.

There are several limitations of our study. First, there was no imaging to confirm fusion. The surgeons in this study do not routinely perform CT scans at 1-year followup to document fusion, and without any confirmation from imaging, there is no way to evaluate the consistency or quality of the fusions achieved here. Second, as the followup was short term, late complications such as pseudoarthrosis may not yet be evident; in particular, if the MIS approach is less effective at achieving fusion, the followup at 1 year will not be sufficient to detect clinical problems related to this issue. Third, the ODI as an outcome tool is not specific for the sacroiliac joint and may be insensitive in assessing functional recovery between treatments.

Other limitations include the retrospective nature of this study. While all patients operated on were evaluated using patient-reported outcome measures, there are well-recognized limitations in this methodology. Although both surgeons are skilled, experienced surgeons, each has a different scope of practice (trauma versus spine). Also, patient selection criteria for sacroiliac joint fusion are not well established. There was a similar approach between the two surgeons, but there likely were some differences between them in terms of when and how surgery was proposed to patients with the diagnosis of chronic sacroiliac joint pain. Typically, the treating surgeons insisted on a trial of nonoperative management, including physical therapy supervised by therapists with interest and experience in treating patients with sacroiliac joint problems. Physical examination had to be concordant with the diagnosis. Subsequently, we are now employing a more structured physical examination, including documentation of the Fortin finger test, tenderness to palpation of the posterior superior iliac spine, posterior thigh thrust, flexion abduction external rotation test, pelvic gapping, pelvic compression, Gaenslen's test (differential pelvic shear testing), and sacral thrust. A confirmatory image-guided diagnostic block of the sacroiliac joint with a greater than $50 \%$ relief of symptoms commensurate with the local anesthetic was also utilized. How much greater than 50\% as reported by the patient to the surgeon or to the physician performing the injection had some variation.

Another limitation is the confounding issue of concomitant pain generators, which remains a clinical challenge. Trying to rule out hip or spine pathology as the pain generator is problematic. Initial patient history and physical examination provided some insight. In cases of ambiguity, a diagnostic hip injection was performed and believed to be reliable for ruling out the hip. The spine was more problematic. Axial imaging was commonly used, and if abnormal, epidural steroid injections, selective nerve root blocks, or facet injections were done. However, there was not an a priori algorithm established, as this thought process is evolving. Finally, not all patients with sacroiliac joint pain were offered surgery. It is the impression of the two surgeons in this report that patients who have had previous spine surgery, especially fusions, see less benefit than those without concomitant spinal pathology. In addition, psychologic factors, although not well quantified to date, also seem to play a role. Only when the surgeons believed that the potential to benefit exceeded the potential to harm were the patients offered surgery. Objectively 
quantifying the surgeon thought processes to date is elusive.

Further, the specificity of the ODI may not be ideal for sacroiliac joint dysfunction as the change in scores in both of our cohorts achieved the minimum clinically important difference for the ODI [6], and the ODI is probably not a tool with good discrimination between sacroiliac joint pain and concomitant spine issues.

Finally, there were differences between groups in postoperative rehabilitation regimens, 3 weeks versus 6 weeks of limited weightbearing. This may or may not play an important role in the outcomes. Likewise, there were some baseline and surgical characteristics that might have been important but were not recorded in this study, including the length of sacroiliac joint symptoms before surgery, the precise response to preoperative diagnostic sacroiliac joint injection, and the last vertebral segment instrumented (for those with prior surgery); as these parameters were not consistently recorded, they could not be compared between the study groups.

Complications and the absence of long-term followup with the MIS procedure are other concerns. Reported complications of the MIS procedure in other work include compression of the L5 nerve root, radiculitis secondary to implant penetration in the sacral neuroforamen, and iliac fracture [17]. This study did not compare the procedure in terms of complications. Open sacroiliac fusion may still be more appropriate in cases where patient anatomy is atypical or when revision surgery for nonunion is required. The obvious advantage of open sacroiliac joint fusions over MIS is the ability to perform a formal cartilage denudation and autologous bone grafting. It is important to take into account that the MIS group was exposed to a larger dose of radiation with the use of $\mathrm{O}$-arm navigation. We believe a rough estimate is that each $\mathrm{O}$-arm spin is equivalent to 40 seconds of fluoroscopy. Furthermore, long-term outcomes for open sacroiliac joint fusion have been reported with good results [10], in contrast to MIS techniques where long-term outcomes have yet to be reported.

Potential advantages of MIS sacroiliac joint fusion technique include a small incision, minimal blood loss, relatively short operating time, decreased soft tissue disruption, and a shorter hospital stay. These parameters have been implicated in minimizing the risk for surgical site infection in other spinal surgical procedures [13, 16, 21].

Buchowski et al. [4] reported good radiographic and functional outcomes after traditional open techniques of sacroiliac joint arthrodesis for nontraumatic sacroiliac joint pain/dysfunction diagnosed by physical examination and intraarticular sacroiliac joint injections for patients failing nonoperative management. They reported $85 \%$ solid fusion rate and significant improvement based on SF-36 questionnaires. Similarly, percutaneous sacroiliac joint fixation has also been reported to have good results in SF-36 scores and fusion rates $[1,9,17,18,27]$. We found improvements in both treatment groups and no difference between groups in postoperative ODI after controlling for age, sex, BMI, spine surgery history, and preoperative ODI.

In conclusion, this study has raised important points that may be considered in the choice of open or MIS sacroiliac joint arthrodesis. Decreases in EBL, surgery time, and LOS were observed for MIS sacroiliac joint fusion compared to the open technique. The effectiveness of the two sacroiliac joint fusion techniques appears to be comparable as suggested by similar ODI scores between the two groups. However, because the implants used for these procedures make assessment of fusion challenging with available imaging techniques, we do not know how many patients' sacroiliac joints successfully fused, so longer followup and critical evaluation of outcomes scores over time are called for.

\section{References}

1. Al-Khayer A, Hegarty J, Hahn D, Grevitt MP. Percutaneous sacroiliac joint arthrodesis: a novel technique. J Spinal Disord Tech. 2008;21:359-363.

2. Bernard TN Jr, Cassidy JD. The Sacroiliac Joint Syndrome: Pathophysiology, Diagnosis and Management. New York, NY: Raven Press; 1991.

3. Bernard TN Jr, Kirkaldy-Willis WH. Recognizing specific characteristics of nonspecific low back pain. Clin Orthop Relat Res. 1987;217:266-280.

4. Buchowski JM, Kebaish KM, Sinkov V, Cohen DB, Sieber AN, Kostuik JP. Functional and radiographic outcome of sacroiliac arthrodesis for the disorders of the sacroiliac joint. Spine J. 2005;5:520-528; discussion 529.

5. Chan KF. Musculoskeletal pain clinic in Singapore-sacroiliac joint somatic dysfunction as cause of buttock pain. Ann Acad Med Singapore. 1998;27:112-115.

6. Copay AG, Glassman SD, Subach BR, Berven S, Schuler TC, Carreon LY. Minimum clinically important difference in lumbar spine surgery patients: a choice of methods using the Oswestry Disability Index, Medical Outcomes Study questionnaire Short Form 36, and pain scales. Spine J. 2008;8:968-974.

7. Gemmell HA, Jacobson BH. Incidence of sacroiliac joint dysfunction and low back pain in fit college students. J Manipulative Physiol. Ther. 1990;13:63-67. 6

8. Katz V, Schofferman J, Reynolds J. The sacroiliac joint: a potential cause of pain after lumbar fusion to the sacrum. $J$ Spinal Disord Tech. 2003;16:96-99.

9. Khurana A, Guha AR, Mohanty K, Ahuja S. Percutaneous fusion of the sacroiliac joint with hollow modular anchorage screws: clinical and radiological outcome. J Bone Joint Surg Br. 2009;91:627-631.

10. Kibsgard TJ, Roise O, Sudmann E, Stuge B. Pelvic joint fusions in patients with chronic pelvic girdle pain: a 23-year follow-up. Eur Spine J. 2013;22:871-877.

11. Kirkaldy-Willis WH. Five common back disorders: how to diagnose and treat them. Geriatrics. 1978;33:32-33, 37-41.

12. Kirkaldy-Willis WH, Hill RJ. A more precise diagnosis for lowback pain. Spine (Phila Pa 1976). 1979;4:102-109. 
13. Kurmann A, Vorburger SA, Candinas D, Beldi G. Operation time and body mass index are significant risk factors for surgical site infection in laparoscopic sigmoid resection: a multicenter study. Surg Endosc. 2011;25:3531-3534.

14. Lorio MP, Polly DW Jr, Ninkovic I, Ledonio CG, Hallas K, Andersson G. Utilization of minimally invasive surgical approach for sacroiliac joint fusion in surgeon population of ISASS and SMISS membership. Open Orthop J. 2014;8:1-6.

15. Maigne JY, Aivaliklis A, Pfefer F. Results of sacroiliac joint double block and value of sacroiliac pain provocation tests in 54 patients with low back pain. Spine (Phila Pa 1976). 1996;21: 1889-1892.

16. Pull ter Gunne AF, Cohen DB. Incidence, prevalence, and analysis of risk factors for surgical site infection following adult spinal surgery. Spine (Phila Pa 1976). 2009;34:1422-1428.

17. Rudolf L. Sacroiliac joint arthrodesis-MIS technique with titanium implants: report of the first 50 patients and outcomes. Open Orthop J. 2012;6:495-502.

18. Rudolf L. MIS fusion of the SI joint: does prior lumbar spinal fusion affect patient outcomes? Open Orthop J. 2013;7:163-168.

19. Schwarzer AC, Aprill CN, Bogduk N. The sacroiliac joint in chronic low back pain. Spine (Phila Pa 1976). 1995;20:31-37.

20. Sembrano JN, Polly DW Jr. How often is low back pain not coming from the back? Spine (Phila Pa 1976). 2009;34:E27-E32.
21. Skramm I, Saltyte Benth J, Bukholm G. Decreasing time trend in SSI incidence for orthopaedic procedures: surveillance matters! J Hosp Infect. 2012;82:243-247.

22. Slinkard N, Agel J, Swiontkowski MF. Documentation of outcomes for sacroiliac joint fusion: does prior spinal fusion influence the outcome? Eur Spine J. 2013;22:2318-2324.

23. Slipman CW, Lipetz JS, Plastaras CT, Jackson HB, Vresilovic EJ, Lenrow DA, Braverman DL. Fluoroscopically guided therapeutic sacroiliac joint injections for sacroiliac joint syndrome. Am J Phys Med Rehabil. 2001;80:425-432.

24. Slipman CW, Sterenfeld EB, Chou LH, Herzog R, Vresilovic E. The value of radionuclide imaging in the diagnosis of sacroiliac joint syndrome. Spine (Phila Pa 1976). 1996;21:2251-2254.

25. Slipman CW, Sterenfeld EB, Chou LH, Herzog R, Vresilovic E. The predictive value of provocative sacroiliac joint stress maneuvers in the diagnosis of sacroiliac joint syndrome. Arch Phys Med Rehabil. 1998;79:288-292.

26. Spiker WR, Lawrence BD, Raich AL, Skelly AC, Brodke DS. Surgical versus injection treatment for injection-confirmed chronic sacroiliac joint pain. Evid Based Spine Care J. 2012;3: $41-53$.

27. Wise CL, Dall BE. Minimally invasive sacroiliac arthrodesis: outcomes of a new technique. J Spinal Disord Tech. 2008;21: $579-584$. 